Revista Docência do Ensino

Superior

v. 2, 2012

Zulmira Medeiros

UFMG

Maria de Lourdes Coelho UFMG

Bianca Rückert

UFMG

Bréscia França Nonato

UFMG

Helen Cristina do Carmo UFMG

\section{APRENDIZAGEM COLABORATIVA EM CURSOS SEMI-PRESENCIAIS DE FORMAÇÃO EM DOCÊNCIA DO ENSINO SUPERIOR}

\section{COLLABORATIVE LEARNING IN SEMI-ATTENDING UNDERGRADUATION TEACHING TRAINING}

\title{
RESUMO
}

Este artigo apresenta uma análise de atividades realizadas em um ambiente virtual de aprendizagem associadas a atividades presenciais, com o objetivo de contribuir com metodologias que visem a uma aprendizagem colaborativa em rede. Nesse sentido, os alunos trabalham coletivamente, de forma a minimizar a centralidade da figura dos tutores e a favorecer a participação, a colaboração, as iniciativas e a autonomia dos próprios alunos. $\mathrm{O}$ estudo realizouse na Universidade Federal de Minas Gerais, no âmbito da formação docente para o ensino superior - uma ação do Programa de Apoio a Planos de Reestruturação e Expansão das Universidades Federais - REUNI. Neste artigo, apresentamos os elementos teóricos que sustentaram o trabalho e a análise dos recursos e procedimentos didáticos utilizados. Os resultados obtidos apontam práticas de mediação que propõem o uso das tecnologias de informação e comunicação de forma inovadora e colaborativa.

Palavras-Chave: Aprendizagem colaborativa. Ensino superior.

\section{ABSTRACT}

This paper presents an analysis of some activities carried through a virtual learning environment associated to face to face activities and aims to contribute to methodologies related to collaborative network learning. In this way, students work collectively, decreasing the centralization of the tutors and promoting the participation, the collaboration, the initiatives and the autonomy of themselves. The study took place at UFMG (Federal University of Minas Gerais) in the context of a program for restructuring and expanding Federal Universities - REUNI. In this paper, we present the theoretical background for this work and the analysis of the resources and didactic procedures. The results found point out practices of mediation that consider the use of information and communication technologies in an innovative and collaborative direction.

Keywords: Collaborative learning. Higher education. 


\section{CONTEXTUALIZANDO A PESQUISA}

Durante a última década, o governo brasileiro colocou em prática uma série de medidas objetivando sanar o déficit de vagas no ensino superior em nosso país. Uma das políticas de expansão universitária voltadas para a rede federal de ensino superior foi o Programa de Apoio a Planos de Reestruturação e Expansão das Universidades Federais - REUNI. Esse Programa possui metas quantitativas, como a ampliação dos espaços presenciais e também da modalidade educacional a distância, e qualitativas, como: flexibilização curricular, renovação de práticas pedagógicas, uso de tecnologias de apoio à aprendizagem e articulação entre a graduação e a pós-graduação (BRASIL, 2007).

O Programa REUNI contou com a adesão de todas as Universidades Federais, entre elas a Universidade Federal de Minas Gerais - UFMG. Para essas instituições foi previsto o financiamento para a expansão do número de vagas e de cursos no ensino de graduação e de pós-graduação, novas vagas de docentes e de funcionários técnicoadministrativos e a ampliação de recursos materiais. O novo quadro propõe também o envolvimento dos estudantes de pós-graduação nas atividades docentes, mediante o recebimento de bolsas, conforme previsto pelo Programa.

Como mestrandas e doutorandas em Educação na UFMG, acompanhamos a criação do GIZ - Rede de Desenvolvimento de Práticas de Ensino Superior, uma diretoria vinculada à Pró-Reitoria de Graduação e que possui como meta atender a demanda pela formação de professores para o ensino universitário, bem como favorecer a implementação de novas metodologias e tecnologias no ensino. Dentre as ações do GIZ está o Curso "Formação em Docência do Ensino Superior", que promove a formação dos alunos dos programas de mestrado e doutorado da UFMG, preferencialmente bolsistas REUNI.

Tal formação se inscreve em uma estratégia de profissionalização do ofício de professor, que rompe o pressuposto de que para ser professor basta ter domínio dos conhecimentos científicos a serem ensinados. Diferentemente, tal perspectiva percebe este ofício como objeto de formação, para o qual é necessário domínio teórico e prático dos processos de ensino e aprendizagem (PERRENOUD, 2002, p. 10). Por se tratar de um Curso que tem como público-alvo estudantes de pós-graduação, dos quais muitos vivenciam pela primeira vez a experiência de ser docente, ele se caracteriza como formação inicial de professores. 
O Curso é semestral, semipresencial, com cinco encontros presenciais e o uso de um ambiente virtual de aprendizagem. A carga horária total é de 60 horas, sendo 20h presenciais e 40h a distância. Desde a primeira oferta em 2008, foram atendidas onze turmas de aproximadamente 35 participantes em cada uma, sendo que as duas últimas o concluíram ao término do primeiro semestre de 2011. As atividades a distância são realizadas por meio da plataforma MOODLE¹, que é um software livre, adotado em diversas instituições no mundo inteiro, para atividades no ensino a distância ou como apoio ao ensino presencial.

O conteúdo programático é composto pelos seguintes módulos temáticos: participação em EAD; docência na universidade; concepções de ensino e aprendizagem; planejamento do ensino; avaliação da aprendizagem. O primeiro módulo tem como objetivo ambientar os participantes na plataforma MOODLE e apresentar alguns elementos essenciais da Educação a Distância, como o gerenciamento do tempo e da aprendizagem. Os outros quatro módulos temáticos propõem discutir os temas referidos a cada um deles, de forma reflexiva, a partir de diferentes atividades realizadas no ambiente virtual e nos encontros presenciais.

Sabemos que a utilização das novas tecnologias nas atividades presenciais e a distância demanda novas metodologias e estratégias de ensino e aprendizagem diferenciadas. Acreditamos, por isso, que todos os envolvidos no processo educativo, tanto professores quanto os bolsistas pós-graduandos, estão em processo de formação. Deles são exigidos novos saberes, competências e habilidades para a efetivação de suas práticas de ensino e de aprendizagem, justificando a realização do Curso de "Formação em Docência do Ensino Superior" com uma plataforma de ensino a distância. Além disso, ofertar cursos totalmente presenciais exigiria desse público disponibilidade em suas agendas já tão comprometidas com o cumprimento de créditos em disciplinas, os afazeres da pesquisa e as atividades de apoio à docência inerentes à bolsa REUNI.

Assim, o formato semipresencial mostrou-se deveras coerente com a demanda e seu contexto, possibilitando momentos presenciais de intensa troca comunicativa, além de atividades realizadas a distância.

\footnotetext{
1 Modular Object-Oriented Dynamic Learning Environment - Moodle é um software livre, de apoio à aprendizagem, executado num ambiente virtual. É desenvolvido colaborativamente por uma comunidade virtual, que reúne programadores e desenvolvedores de software livre, administradores de sistemas, professores, designers e usuários de todo o mundo. Muitas instituições de ensino (básico e superior) e centros de formação estão adaptando a plataforma aos próprios conteúdos, não apenas para cursos a distância, mas também como apoio aos cursos presenciais (Fonte: http:/ / pt.wikipedia.org/wiki/Moodle).
} 
Como bolsistas REUNI e integrantes da equipe de formação do GIZ, participamos do planejamento, execução e avaliação do Curso, assim como da elaboração dos relatórios ao final de cada semestre. Tal vivência nos possibilitou um acompanhamento sistemático através de pesquisas para registrar, avaliar, validar e/ou vislumbrar novas possibilidades de intervenção.

Durante cada oferta do Curso, os cursistas são chamados a avaliar o processo. Ao final de cada encontro presencial, são realizadas avaliações parciais por escrito, buscando acompanhar o dia-a-dia do Curso. Após o último encontro presencial, é disponibilizado no ambiente virtual, durante cerca de quinze dias, um questionário com questões fechadas e abertas a fim de possibilitar o registro das apreciações dos alunos sobre o Curso, a metodologia, a atuação das professoras, bem como sobre a própria participação e aprendizagem, ou seja, uma autoavaliação. Os dados coletados presencial e virtualmente são categorizados e analisados durante cada Curso, podendo indicar, ao longo do tempo, os ajustes necessários, as lacunas, assim como os acertos e o que deve ter continuidade, tanto para a oferta atual como para as seguintes.

Nos próximos tópicos, apresentaremos, de forma descritiva e avaliativa, algumas das atividades presenciais e outras realizadas no ambiente virtual de aprendizagem. Traremos, ao longo do texto, excertos das avaliações dos alunos, no intuito de explicitar a percepção desse público em relação à metodologia adotada no Curso.

\section{PLANEJAMENTO - INTEGRANDO O PRESENCIAL E O VIRTUAL}

Ao planejarmos o Curso, buscamos, a cada módulo, contemplar a organização do encontro presencial e a construção do ambiente virtual. $\mathrm{O}$ objetivo de tal perspectiva é garantir que os momentos presenciais e virtuais dialoguem e se completem. Desta forma, o planejamento de cada encontro foi pensado no sentido de dar continuidade à discussão sobre determinado tema iniciado no virtual, cuja reflexão foi provocada inicialmente por um vídeo ilustrativo, aprofundada pelas leituras propostas nos textos disponibilizados no ambiente e pelos relatos de experiências de estudantes de ensino superior, escritos no memorial. As atividades presenciais iniciaram-se com uma técnica de dinâmica de grupo, proporcionando a acolhida dos participantes e uma reflexão introdutória. Em seguida, foram desenvolvidas atividades em grupo para estudo dos textos de referência, apresentações de análises e sínteses e, para finalizar, uma sistematização dos conceitos trabalhados com apresentações de slides. Foi previsto um tempo para cada atividade e um revezamento da condução entre as tutoras. 
Tendo em vista que se trata de um Curso voltado para discutir a docência no Ensino Superior a partir da reflexão sobre a própria prática pedagógica, nos encontros presenciais foram realizadas atividades com propostas metodológicas diferenciadas, a fim de que os alunos percebam múltiplas possibilidades de inovação em sua prática pedagógica.

Apoiamos nossas ações no acompanhamento aos alunos durante o Curso com ênfase na aprendizagem. Dessa forma, com base nos estudos de Gil (2007), acreditamos que nosso papel foi de "ajudar o aluno a aprender", e não de ensinar, considerando as seguintes questões ao planejar as atividades e ao escolher os recursos: “Quais as expectativas dos alunos? Em que medida determinado aprendizado poderá ser significativo para eles? Quais as estratégias mais adequadas para facilitar seu aprendizado?" (p. 7).

Consideramos que, na relação entre professor e alunos universitários, os sujeitos envolvidos são adultos ou que os estudantes estejam entrando nessa fase da vida e que, assim sendo, as ações pedagógicas requerem a participação mais ativa dos mesmos. Dessa forma, ao planejarmos o curso, selecionamos conteúdos e atividades que fossem significativos para os estudantes, com margem para a participação deles nas definições das tarefas e com "utilização de procedimentos de avaliação diretamente relacionados à aprendizagem" (GIL, 2007, p.13).

Assim, buscamos em nosso planejamento conciliar atividades diversas, contemplando momentos individuais, coletivos, aprofundamento teórico, diversificando as formas de aprendizado. E para além das atividades que objetivam o aprendizado, também prezamos pelos momentos de acolhimento, garantindo o entrosamento dos alunos entre si e com as tutoras.

\section{TÉCNICAS DE DINÂMICAS DE GRUPO E TAREFAS COLETIVAS}

Os encontros presenciais são iniciados com uma técnica de dinâmica de grupo, através da qual se proporciona a acolhida dos participantes pelas tutoras e deles entre si, o que permite maior sociabilidade entre o grupo. Tais técnicas caracterizam-se por serem curtas (de 15 a 30 minutos), partirem de elementos lúdicos, tais como músicas, imagens ou brincadeiras, e por culminarem numa breve reflexão que relacione a atividade executada com o tema em estudo. Além da introdução dos temas de forma animada e cria- 
tiva, todas as técnicas apresentam caráter pedagógico e objetivam que os alunos reflitam sobre sua prática docente.

Considerando que a educação deve ser compreendida como processual e dialógica, prioriza-se no Curso atividades que contemplem o aprendizado coletivo. Tais atividades, propostas num segundo momento do encontro, possuem duração maior (de 1 a 2 horas), partem do trabalho em pequenos grupos ( 3 a 6 pessoas) e culminam geralmente na socialização das discussões em um grande círculo. A centralidade das tutoras é diluída, tornando-as facilitadoras do processo.

Na experiência analisada, tais atividades presenciais têm sido avaliadas pelos discentes como produtivas, como pode ser observado nos depoimentos dos alunos:

Os encontros presenciais foram excelentes, de forma que não consigo imaginar tal curso sem estes encontros. O uso de dinâmicas de grupo, seguidos de aulas com técnicas variadas e consecutivos seminários foram adequados para que a organização das atividades possibilitasse um maior intercâmbio de conhecimentos entre os participantes e entre estes e as professoras/monitoras.

... me empolgavam em relação ao curso. Saia cheia de ideias para as aulas. Entre um encontro e outro me sentia um pouco desestimulada, mas bastava ir ao encontro presencial que me empolgava novamente. O melhor do curso foram os encontros presenciais!

O encontro presencial é um momento único de socialização, de se compartilhar saberes e vivências, daí a grande ênfase dada às atividades coletivas e aos debates, através dos quais, expressando-se em discussão com os pares, os discentes (re)elaboram conhecimentos necessários à prática docente.

A heterogeneidade do grupo e a sistematização dos conteúdos por parte das "facilitadoras" também contribuem significativamente para o aprendizado dos alunos. Nesse sentido, podem ser destacados como pontos importantes: a discussão em grupo; o debate e interação com colegas das diferentes áreas do conhecimento; a socialização das experiências na docência; e a possibilidade de tirar as dúvidas teóricas e técnicas no momento em que elas aparecem.

\section{O SUPORTE TEÓRICO}

A proposta do Curso apresenta como um dos elementos centrais a construção de uma postura reflexiva sobre a prática educativa. Esse processo é desenvolvido principalmente através das técnicas de dinâmicas de grupo adotadas nos encontros presenciais 
e nas atividades virtuais, como os fóruns e memoriais. Paralelo à criação desses espaços de reflexão e análise, busca-se desenvolver o estudo de saberes didáticos transversais, que têm como proposta direcionar o olhar e a reflexão sobre a realidade.

Busca-se, dessa forma, desenvolver uma formação que amplie as bases científicas da prática docente, articulando racionalidade científica e prática reflexiva como duas faces da mesma moeda. Com isso, evita-se a construção de 'receitas' para os dilemas didáticos que perpassam o ofício do professor, principalmente o iniciante; e busca-se a construção de uma postura reflexiva, de um profissional que se dispõe a "abandonar imagens estereotipadas da profissão e da formação de professores" (PERRENOUD, 2002, p. 18).

Nesse sentido, a bibliografia básica do Curso inicia com uma reflexão epistemológica sobre a aula universitária - inovação pedagógica (VEIGA; RESENDE; FONSECA, 2000) e concepções do processo de ensino e aprendizagem (GIUSTA, 2007) - e perpassa pelas temáticas do planejamento do ensino (GIL, 2007) e da avaliação da aprendizagem (PERRENOUD, 1999). Por apresentarem o planejamento como práxis e a avaliação como processo formativo, tais referências buscam, na reflexão sobre a docência, um dos elementos centrais da proposta do Curso.

\section{ORGANIZAÇÃO DO AMBIENTE VIRTUAL DE APRENDIZAGEM}

O ambiente virtual se configura como importante espaço de aprendizagem, servindo como suporte para atividades realizadas durante toda a formação. De maneira geral, a sua organização é pensada de forma a facilitar o acesso aos recursos necessários para as atividades do Curso e a incentivar ao máximo a interação virtual.

Logo na abertura da página, os alunos têm acesso às informações para execução das atividades propostas para a semana. Em seguida, encontra-se uma série de recursos (fóruns de notícias, plano de curso, orientações) que servem como suporte para interações e informações mais gerais.

Além destes espaços, o ambiente é dividido em unidades de estudos de acordo com os cinco módulos propostos no Curso. Em cada um desses tópicos, os alunos têm acesso às atividades (fóruns, memorial, glossário, dentre outras), orientações sobre como realizá-las, indicações de leituras, etc.

Por fim, o ambiente virtual conta com uma ampla midiateca, onde são disponibilizados os textos essenciais e complementares aos estudos das unidades, vídeos, 
links para sites relacionados aos temas, referências de filmes, facilitando o acesso dos alunos aos materiais e oferecendo recursos para o aprofundamento dos temas abordados na formação.

\section{FÓRUNS VIRTUAIS: ESPAÇOS DE CONSTANTE INTERAÇÃO}

No intuito de também refletir sobre as relações entre as tecnologias e a educação, no ambiente virtual são criados fóruns com temáticas e finalidades diferenciadas. No primeiro deles, o 'Fórum de apresentação', os alunos se apresentam e têm seu primeiro contato com a sala de aula do ambiente virtual. Em seguida, ainda num período de ambientação, é proposto o 'Fórum sobre o tempo', onde os alunos conversam sobre educação a distância e a administração do tempo. Para tratar de dúvidas referentes ao Curso e à plataforma MOODLE, fica disponível para os alunos o 'Fórum operacional' . Nessa sala de aula, também há a 'Hora do intervalo', um fórum criado para as conversas informais, divulgação de eventos, trocas de materiais e mensagens diversas, um espaço livre para os alunos. O 'Fórum de notícias' é utilizado para a postagem de informações e avisos sobre o Curso ou eventos afins.

Com foco nas atividades de aprendizagem, há os fóruns chamados 'Cafés pedagógicos', onde se estabelece um espaço de discussão abordando as questões relativas ao tema de cada módulo, oferecendo-se subsídios ilustrativos e teóricos.

Com o intuito de aderir a um currículo dinâmico, tendo como referência os sujeitos envolvidos, busca-se tornar os fóruns espaços de interação social e de aprendizagem amplo. Esse espaço de discussão teórica possibilita a ampliação dos debates feitos nos encontros presenciais, com o ganho de permitir aos alunos maior elaboração teórica dos temas discutidos. De forma similar, os fóruns também levam para as atividades presenciais, dúvidas e questionamentos provenientes das discussões do ambiente virtual.

\section{MEMORIAL DA EXPERIÊNCIA DISCENTE E CÍRCULO DE APOIO MÚTUO}

O Memorial é uma atividade de escrita e análise de vivências, que tem como objetivo dar sentido ao vivido e construir um conhecimento a partir deste. Parte da concepção do saber que vem da experiência, assim como proposto por Larrossa (2002), que afirma que, se "a experiência é o que nos passa, o que nos acontece, o que nos toca" (p. 21); e o 
saber que vem dela "está na relação entre o conhecimento e a vida humana. (...), ela é, portanto, uma espécie de mediação entre ambos" (p. 26-27).

Partindo desses pressupostos, neste Curso o memorial visa dar sentido às experiências de discentes na graduação e, assim, construir um conhecimento no âmbito da docência do ensino superior. Sobre esse aspecto, Pimenta e Anastasiou (2005) enfatizam "a importância da construção do memorial ou história de vida como recurso a ser desenvolvido com os alunos, como forma de autoconhecimento e tomada de decisão na vida universitária" (p. 29).

Nesta atividade, os alunos são chamados a escrever histórias que tenham sido significativas em relação a: a) um professor marcante; b) uma aula ou disciplina marcante; c) uma experiência avaliativa marcante. Ao escreverem sobre temas que coincidem com estudos dos referenciais, os alunos trazem elementos teóricos que subsidiam as análises dos memoriais.

Paralelamente, ocorre o Círculo de Apoio Mútuo, atividade organizada de acordo com a ordem alfabética dos primeiros nomes dos participantes. Propõe-se que o primeiro da lista leia e comente o memorial do segundo e assim sucessivamente, até que o último leia e comente o memorial do primeiro, para que o círculo se feche. Tanto os memoriais quanto os comentários são escritos no blog do ambiente virtual.

Tece-se, assim, uma rede de interações, onde se percebe a construção de um diálogo sobre as experiências e dessas com os referenciais, tendo em vista o caminhar para a produção de novos sentidos e para um nível mais complexo de análise da prática docente. No caso das experiências narradas no curso, o que se observa é um deslocamento do olhar do discente para o docente na sua fase inicial, o que só é possível à medida que se aprofunda as bases científicas da prática, conforme ressaltado por uma aluna em seu memorial:

Devo mencionar que estar do lado do professor é uma experiência muito nova e os textos e fóruns estão contribuindo para que eu pense "além" do lado de ser aluno. Como comentei outro dia no encontro presencial passei 99,9\% da vida como aluno e agora começo a me reposicionar e ver o lado de ser professor. A questão processual, mencionada por MASETTO e tantos outros autores indicados, sempre foi importante pra mim como aluno na graduação. Mas eu não sabia dar "nome" a isso. Agora tenho a ver a importância deste "tipo" de ensino-aprendizagem que tendo a acreditar e querer cada vez mais colocar em prática. (Estas aspas aí acima representam outra novidade: o vocabulário que se forma e ainda tem muitas lacunas para serem preenchidas). 
Nesse contexto, o Círculo de Apoio Mútuo se apresenta como um importante espaço de diálogo sobre o vivido e de construção de rede na turma, na medida em que, conforme destacado pelos alunos, funciona como uma técnica que visa justamente facilitar a interação entre os participantes e a acolhida de uns para com os outros. Potencializa, assim, as relações de apoio, empatia e coletividade entre os alunos. Observa-se um sentimento de que, para seu funcionamento, demanda-se o envolvimento de todos, pois do contrário, há uma quebra nas trocas.

É importante ressaltar que o Círculo de Apoio Mútuo, de forma alguma, substitui o papel do comentário da equipe de tutoria. Este, inclusive, foi indicado como um dos momentos de maior estreitamento na relação pedagógica do Curso. Através dos comentários, foi possível à equipe de tutoria contribuir para que os cursistas aprofundassem suas reflexões, relacionassem suas vivências com outros conhecimentos científicos, além de darem mais um passo na mudança de lugar - de discentes para docentes.

Com isso, a experiência do memorial nos mostra que, através da reflexão sobre as marcas deixadas pelos seus professores na graduação e sobre as necessidades do estudante universitário atual, o Curso contribui para que seus egressos possam "ensinar de modo diferente de como foram ensinados por seus antigos mestres" (PIMENTA e ANASTASIOU, 2005, p.188).

\section{CONSIDERAÇÕES FINAIS}

Apresentando esta breve análise descritiva de algumas das atividades realizadas nos encontros presenciais e no ambiente virtual, podemos perceber que, neste Curso, o ambiente virtual amplia a sala de aula, ao mesmo tempo em que os encontros presenciais materializam o ambiente virtual.

A rede criada estabelece entre os participantes (alunos e tutores) uma relação didática diferenciada, marcada pelo comprometimento com as atividades individuais e coletivas, gerando uma responsabilização pelo outro e pelo próprio processo de formação. Exemplo disso está na efetiva participação dos alunos, tanto para desenvolver trabalhos em grupo, quanto para a troca de leituras e comentários dos memoriais.

Destacamos o crescimento do grupo por meio da reflexão sobre as vivências discentes, provocadas principalmente pela escrita e compartilhamento do memorial, através do Circulo de Apoio Mútuo no ambiente virtual, e dos relatos de experiências 
em sala de aula, durante os trabalhos em grupo e a socialização com toda a turma presencialmente.

Destacamos também o aprendizado a partir dos recursos disponibilizados no ambiente virtual, como vídeos e textos digitalizados, das discussões realizadas nos fóruns específicos de cada módulo, além de outras atividades realizadas, ora individualmente, ora coletivamente, sempre buscando a participação colaborativa e o uso pedagógico das tecnologias digitais.

Desta forma, através do Curso, ao mesmo tempo em que se propõe estudar os temas relacionados à docência, oportuniza-se aos cursistas conhecer as ferramentas e utilizá-las pedagogicamente. Acreditamos ser essa uma maneira peculiar de formação, ou seja, ao vivenciarem a utilização das ferramentas tecnológicas como alunos, estarão se preparando para utilizá-las como docentes e incluírem-nas como recursos nos futuros planejamentos das disciplinas, conscientes de suas possibilidades e limitações.

\section{REFERÊNCIAS}

BRASIL. Decreto 6.096 de 24 de abril de 2007. Institui o Programa de Apoio a Planos de Reestruturação e Apoio e Expansão das Universidades Federais - REUNI. Brasília: MEC, 2007.

GIL, A. C. Didática do Ensino Superior. São Paulo: Atlas, 2007.

GIUSTA, A. S. Concepções do processo ensino-aprendizagem. In A. S. GIUSTA \& I. M. FRANCO. Educação a distância: uma articulação entre a teoria e a prática (pp. 45-74). Belo Horizonte: PUC Minas Virtual, 2007.

LARROSSA, J. Notas sobre a experiência e o saber da experiência. Revista Brasileira de Educação. Jan/Fev/Mar/Abr, 2002.

PERRENOUD, P. A avaliação entre duas lógicas. In P. PERRENOUD. Avaliação: da excelência à regulação das aprendizagens. (pp. 9-23). Porto Alegre: Artmed Editora, 1999.

PERRENOUD, P. A prática reflexiva no ofício de professor: profissionalização e razão pedagógica. Porto Alegre: Artmed Editora, 2002.

PIMENTA, S. G. \& ANASTASIOU, L. G. C. Docência no Ensino Superior. São Paulo: Cortez, 2005.

VEIGA, I. P.; RESENDE, L. M. G.; FONSECA, M. Aula universitária e inovação. In I. P. VEIGA \& M. E. L. M. CASTANHO. Pedagogia Universitária: a aula em foco (pp. 161-191). Campinas, SP: Papirus, 2000. 